\title{
Correction to: Discussion of the Fault Models of the Northern Marmara Shelf and the Lagoon Küçükçekmece with New Marine Magnetic Data, Turkey
}

\author{
A. Sinan Demirel ${ }^{1} \cdot$ Hakan Alp $^{2} \cdot$ Bedri Alpar $^{1} \cdot$ Denizhan Vardar $^{1}$ \\ Published online: 26 February 2021 \\ (C) Springer Nature Switzerland AG 2021
}

Correction to: Thalassas: An International Journal of Marine Sciences (289)

https://doi.org/10.1007/s41208-021-00289-1

The affiliation of the second author Hakan Alp was published incorrectly. The authors apologize for any inconvenience that it may have caused. The affiliation of Hakan Alp should be "Department of Geophysical Engineering, Istanbul University-Cerrahpaşa, Büyükçekmece, 34500 Istanbul, Turkey."

Publisher's Note Springer Nature remains neutral with regard to jurisdictional claims in published maps and institutional affiliations.

The online version of the original article can be found at https://doi.org/ 10.1007/s41208-021-00289-1

Denizhan Vardar

denizhan@istanbul.edu.tr

1 Institute of Marine Sciences and Management, Istanbul University,

Vefa, 34116 Istanbul, Turkey

2 Department of Geophysical Engineering, Istanbul

University-Cerrahpaşa, Büyükçekmece, 34500 Istanbul, Turkey 